\section{A STUDY ON THE RELATIONSHIP BETWEEN BURNOUT AND JOB SATISFACTION OF IRANIAN EFL TEACHERS WORKING IN UNIVERSITIES AND SCHOOLS}

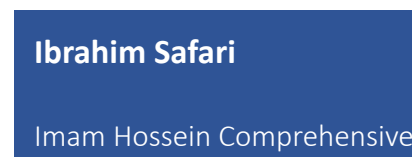

University, Tehran, Iran

safariibrahim1@gmail.com

\begin{abstract}
A teacher plays an important role in the development of the students' potential and helps to form their future. This research intends to study the degree of burnout and job satisfaction in English as a foreign language (EFL) teachers of universities and Schools in Iran, as well as their association with demographic characteristics. To measure teachers' burnout, Maslach Burnout Inventory questionnaire was applied, which has also been validated by experienced teachers for the Iranian population and the Employee Satisfaction Inventory questionnaire, prepared for the Iranian population, was applied to estimate job satisfaction. Questionnaires were answered completely by 159 teachers, who work at universities and schools in Iran. After data analysis, the findings showed a negative correlation between teachers' burnout and their job satisfaction; their experience relatively moderate burnout levels, and their job satisfaction level is high. The findings also represented that the type of workplace influences satisfaction regarding the factor "job conditions". The study was for the first time that Iranian EFL teachers' burnout and job satisfaction in universities and schools were investigated and the findings showed that by increasing the level of job satisfaction, the perceived burnout decreases, where burnout and job satisfaction presented medium to high negative correlation.
\end{abstract}

\section{KEYWORDS}

\section{Burnout, EFL teachers, job satisfaction}

\section{HOW TO CITE}

Safari I. (2020) 'A Study on the Relationship Between Burnout and Job Satisfaction of Iranian EFL Teachers Working in Universities and Schools', Journal on Efficiency and Responsibility in Education and Science, vol. 13, no. 4, pp. 164-173. http://dx.doi. org/10.7160/eriesj.2020.130401

\section{Article history}

Received

April 1, 2020

Received in revised form

May 5, 2020

Accepted

October 19, 2020

Available on-line

December 22, 2020

\title{
Highlights
}

- University teachers have a higher level of job satisfaction and lower burnout in comparison with those who work in schools.

- Sub-scales related to the EFL teachers' job satisfaction have a negative association with their burnout sub-scales.

- By increasing teachers' job satisfaction, their perceived burnout decreases.

\section{INTRODUCTION}

Teachers communicate with large numbers of students, parents, and principals whom each have different demands and problems. This important responsibility as a teacher needs to better understand social norms and values. By a better understanding of the norms and values, teachers can become role models and community will identify with them. According to Maslach, Jackson, and Leiter (1996), the stress experienced by teachers whose job is in direct contact with other people as their recipients of service, is called burnout. Syndromes of burnout emerge in the form of frustration, loss of the job, doubtful attitude towards students, dissatisfaction with selfesteem, and high frequency of changing the job for various reasons.

In Iran, many EFL teachers are highly motivated to teach when they begin to teach. These teachers think of the ways to be more creative and innovative in order to help their students in learning English as a foreign language effectively. They 
like to interchange different ideas with other colleagues and learn new things. Therefore, these teachers may lose the excitement and pleasure of teaching in time, or they may begin seeing their workplace as a stressful environment. Öztürk (2013) stated that the things according to students, colleagues, administration, and coursebooks do not make them happy anymore or these things may even give rise to a negative and stressful psychological condition.

Job burnout can affect the quality of work-life at school. According to the Sitohang (2004), school administrators should be cautious about teachers' situation because they are not only concerned with burnout and teacher job satisfaction but also how to improve the quality of work-life at school. Other consequences of burnout caused by a reduction in job satisfaction. This means that a person's psychological syndrome such as burnout can have a negative impact that it decreases that person's level of job satisfaction therefore increased their degree of absence and increased their carelessness in the job. As stated by Maslach and Jackson (1981: 99), burnout is 'a syndrome of emotional exhaustion and cynicism that occurs frequently among individuals who do 'people-work' of some kind'. Later, Maslach (1982: 3) described burnout as 'a syndrome of emotional exhaustion, depersonalization, and reduced personal accomplishment'. Emotional exhaustion happens when people feel that they have been overextended by contact with other people. Depersonalization related to considering other people as ordinary things or dehumanizing them. Reduced personal accomplishment points out the decrease of self-efficacy on the job or a decline in professional competence (Bibou-Nakou, Stogiannidou, and Kiosseoglou, 1999; Soroor, Afsaneh, and Zargham, 2015).

Another factor related to the EFL teachers, which is extensively discussed in the literature and is expected to affect their career success, is job satisfaction. There is a wide range of research in organizational psychology that considers the strong relationship between job satisfaction of the teachers and the quality of their teaching (Landsman, 2001; Rahman, et al., 2014; Seashore and Taber, 1975). Having a job as one of the determinants of social health is an important part of people's life. As a consequence, job-related conditions and job satisfaction have become one of the essential factors for promoting health and life satisfaction. It concerns the extent to which the job is responsive to the teacher's abilities, needs and personality traits.

According to some researches, job satisfaction has been one of the important subjects in recent years which is a positive emotional condition that arises from the valuation the people's job characteristic and position (Aziri, 2011; Terason, 2018; Vousiopoulos, et al., 2019; Wu, et al., 2016). As stated by Blandford (2000), it can be argued that paying attention to the importance of the concept of job burnout and awareness of factors affecting burnout is significantly increased. Helping people, achieving positive changes and improving students are the main consequences of teachers' job satisfaction and their participation at work.

In the last decades, numerous studies have been done in the fileds of job satisfaction and job burnout. According to Barrick (1989: 35), 'the linkage between stress, job satisfaction, and the work environment is critical to the study of burnout'. As stated by Brewer and McMahan-Landers (2003: 37), 'Misfit between demands and abilities induces coping and defense mechanisms, which in turn influence objective and subjective environments'. Further, Brewer and McMahan-Landers (2003: 126) argued, 'Stress can occur if there is a mismatch between the reality of the work environment (objective) and an individual's perceptions of the work environment (subjective).'. Some of the researchers (Farber, 1998; LeCompte and Dworkin, 1991; Troman and Woods, 2001; Vousiopoulos, et al., 2019) pointed out that those teachers who are stressed for a long time may experience more burnout.

Keeping the two mentioned variables into consideration, changes in the possible associations between these variables are quite likely to affect the outcome of an educational program and therefore need to be widely investigated. In other words, because effective teachers are essential to the achievement of educational goals and objectives, it can be quite clear to examine the factors affecting the burnout and job satisfaction of EFL teachers in particular.

\section{LITERATUE REVIEW}

This section is purporting to present an overview of the theoretical underpinnings of the study as well as the empirical research conducted about the main variables under investigation, namely EFL teachers' burnout and job satisfaction.

\section{Teacher burnout}

Burnout is a psychological stress syndrome when a person in condition with high emotional engagement request for continuous and long extent of time. Teachers' burnout happens when there is inequality between excessive demands and resources available. Teachers who have job burnout, can not succeed and always tackle the failures of the past. According to Johnson et al. (2005), burnout is defined as permanent and deep exhaustion with cognitive, emotional, physical, and social symptoms, arising from long term job stress, especially in professions with high responsibility for others and never-ending human interactions.

According to Azeem (2010), burnout is an important element that negatively influences teachers' job involvement and effectiveness. In this vein, Cephe (2010) pointed out that teaching is a job which is performed in front of individuals and that it's effect may be frustrating not only for teachers but also for students and education systems. Later, Farshi and Omranzadeh (2014) stated, it is necessary to understand the affecting factors on teachers' burnout, measuring the degree of their burnout and preventing them from being burned out. Further, Demirel and Cephe (2015) argued that teachers' burnout is a threat for both sides of the learning and teaching process and that teachers should be free from burnout syndrome to teach effectively. Because burnout can happen in most of the jobs, it seems to be generally known among specialists who enable individuals to deal with their everyday problems (Gavish and Friedman 2010; McCormick, 2011; Rakovec-Felser, 2011; Vousiopoulos, et al., 2019). Thus, jobs like teachersshould have specific capabilities and job skills to control the stressors. Otherwise, they have to wait for results such as depersonalization and emotional exhaustion. 
According to the job demands, teaching became a target audience for burnout symptoms (Jarvis, 2002; Maslach, 1982; Weisberg and Sagie, 1999; Vousiopoulos, et al., 2019). Emotional exhaustion, one of the more extreme varieties of job stress, exhibits itself in teachers as a general loss of feeling, concern, and interest (Van Jaarsveld, 2004) generally bring about absence from the classroom and chronic health problems (Lee, 1990). In this vein, Balkin, White, and Bodey (2003) pointed out that burnout results in a lower quality of teaching, isolation from the society, and early departure from the job. It was argued that burnout predicts subsequent thoughts about leaving the job. As stated by Straquadine (1990), teachers generally find themselves working well beyond a week as they supervise student projects, evaluate their job and prepare lessons. It is argued that the long time working, also the stress of teaching could ultimately result in disabling health problems. Later, Croom (2003: 11) pointed out that 'agriculture teachers appear to be energetic and engaged professionals who were accomplishing something worthwhile for the benefit of students'.

Burnout and job satisfaction have been the issue of intense studies' interest during the last decades. In a study, Sotirios et al. (2019) investigated the teachers' burnout and job satisfaction in the Minority and Public Sector Schools. The findings showed a negative correlation between burnout and job satisfaction; teachers experienced moderate burnout levels, their job satisfaction level was high. The findings also represented that when job satisfaction increases, the perceived burnout decreases, where job satisfaction and burnout presented medium to high negative correlation. In another similar study, Karavasilis (2019) revealed a negative statistical relationship between these variables in which there was a very low degree of burnout syndrome and a high degree of job satisfaction for Greek teachers. In the same vein, Kroupis, Kouli, and Kourtessis (2019) intended to estimate the levels of burnout and job satisfaction among Greek Physical Education teachers. Their findings showed that Greek teachers were more satisfied by the job itself and supervision and dissatisfied by promotion and even more by pay while experiencing medium to low burnout.

Teachers have an important role in developing their students' potential and success. As stated by Roy and Kumar (2018) in their study, job satisfaction is an essential necessity for teachers' commitment towards their responsibilities. Moreover, teachers' burnout is the result of different responsibilities which is given to them. Later, Kara (2020) investigated the burnout and job satisfaction of 308 Turkish teachers in terms of some variables such as age, gender, marital status, experience and workplace. The results showed that teachers' burnout and job satisfaction represented significant differences according to gender, marital status, experience and workplace. Additionally, there was a significant negative relationship between their burnout and job satisfaction.

Although various researches have been done to study teachers' burnout regarding factors like age (Kırılmaz, Çelen and Sarp, 2003; Güven, 2010; Özkanal and Arıkan,
2010), gender (Hastings and Bham, 2003; Güven, 2010), educational background (Kurtoğlu, 2011; Öztürk, 2013), teaching experience (Öztürk, 2013; Ceylan and Mohammadzadeh, 2016), institution (Koruklu et al., 2012), weekly course load (Kurtoğlu, 2011; Öztürk, 2013), administrative duty (Azeem and Nazir, 2008; Konakay and Altaş, 2011), monthly income (Lackritz, 2004; Bilge, 2006; Ceylan and Mohammadzadeh, 2016), few numbers of researches have been conducted to study EFL teachers' burnout regarding the variables in the EFL teaching context.

\section{Teacher Job Satisfaction}

Job satisfaction was defined in different ways according to the social contexts, agrees to the fact that it is a multidimensional concept. As stated by Locke (1976), job satisfaction is an emotional situation as a consequence of people's job experience. Moreover, Spector (1985) indicated job satisfaction as an emotional and perceptual response to the specific characteristic of a job. Further, Wagner and Hollenbeck (1992) argued that job satisfaction is a pleasant feeling that comes from the insight that people's job satisfies or allows for the satisfaction of one's outstanding values came from their work. Later, Tukiran (2014) pointed out, satisfaction and commitment are necessary factors in order to improve the teaching and learning process.

Castillo and Cano (2004) categorized job satisfaction into two types: general satisfaction and specific satisfaction. General satisfaction is the overall and comprehensive satisfaction that is defined as an overall assessment of a people's perception of their work. Specific satisfaction has been defined as an assessment of different aspects of the work. Some of the examples related to these aspects consist of monetary benefits, working conditions, and relationships with colleagues and superiors, and the nature of the work itself (Petty, Brewer, and Brown, 2005; Vousiopoulos, et al., 2019).

According to some of the previously conducted researches (Maslach, Schaufeli and Leiter, 2001; Schaufeli and Enzmann, 1998; Schmidt, Neubach and Heuer, 2007; Taris, 2006; Vousiopoulos, et al., 2019), people who experience burnout often report reduced job satisfaction, cognitive performance impairment, especially fatigue, and physical complaints. Correspondingly, teachers with a high degree of burnout feel dissatisfied at work and experience various physical complaints that ultimately affect their teaching. Additionally, the results were supported by Taris, (2006) which suggested that the higher intrinsic factor of job satisfaction leads to the lower burnout. Accordingly, extrinsic factors of job satisfaction, number of people to teach (overcrowded class), excessive workload, work routines, and the administrative job that goes beyond people ability and capacity.

In the field of teaching, Konert (1997) indicated that teachers who experience job stress also suffers from low personal accomplishment and emotional exhaustion. In another similar study, Tan (2006) represented that job satisfaction has a negative relationship with emotional exhaustion but a positive relationship with the length of time a person is having a career. At the same time, Lim (2005) pointed out that the degree of teachers' stress in Malaysia was low and 
there was a significant inverse correlation between job satisfaction and burnout. Three years later, Anbar and Eker (2008) conducted a study to find the association between job satisfaction and burnout of academics in Turkey. Their findings were in line with the results of Lim's study, in which they found a negative association between job satisfaction and burnout.

Lately, Yu-Hsia and Mei-Hsiang (2019) investigated the relationship between job satisfaction and burnout. The findings indicated that both of the 'personal burnout' and 'external satisfaction' had the highest mean sub-scale score; there was a statistically significant relationship between job satisfaction and burnout; 'personal burnout', 'work-related burnout', and the 'over commitment to work' were related to the 'inner satisfaction' and the 'external satisfaction'. These results provided guidance and evidence for the requirement to increase job satisfaction in order to decrease burnout. In the same year, Wisnu (2019) intended to study the statistical relationship between job satisfaction and burnout. This study found two results: First, emotional exhaustion as one of the sub-scales of burnout had a significant negative effect on job satisfaction. Second, job satisfaction had a significant positive effect on performance.

In another related study, Atmaca (2017) explored the possible causes of burnout in different schools of Turkey. The results demonstrated that there was a low negative relationship between job satisfaction and burnout. The results also showed a relatively strong positive relationship between emotional exhaustion and depersonalization in addition to the strong positive correlation between the intrinsic and extrinsic job satisfaction levels. Accordingly, some main factors such as self-efficacy, shareholders, physical and social environment of the school were found to have a necessary role in EFL teachers' burnout. Similar to the results obtained by previous studies, Robinson et al. (2019) showed that there was a statistically significant relationship between job satisfaction and burnout among special education teachers.

In addition to the studies mentioned above, Torkaman et al. (2017) investigated the statistical relationship between job satisfaction, burnout and job stress among teachers in exceptional schools of Qazvin Province in northwestern Iran. According to the results, there was a direct and significant relationship between job satisfaction and burnout in which Job satisfaction and burnout negatively correlated with the dimensions of stress. It was also revealed that failure to satisfy these teachers' motivational needs over time causes their dissatisfaction with the working process, which result in job burnout and stress. Consequently, interventions to decrease stressors and strengthen the resources to manage teachers' burnout would be an important factor of their job satisfaction.

In one of the related studies, Azlina and Noryati (2012) represented the low level of job satisfaction and job stress at a moderate level. Their findings were consistent with the researches conducted by Norul Azlin (2005) who investigated the degree of stress up to one-hundred and twenty teachers who teach in exam classes in ten primary schools which showed that the overall degree of stress at a low level. As result, the review of the literature indicated that there was a negative association between job satisfaction and burnout among teachers.

Moreover, Higgins (1987) stated that if teachers feel important, and valuable, they will experience job satisfaction as a teacher because they are successful in their job and the consequences are excellent. Higgins also pointed out, achieving job satisfaction puts a person into a balanced state or a state of actual ideal self-gap absence. All in all, job satisfaction is people's like or dislike towards their job and the degree to which their expectations regarding job have been realized.

\section{Problem of the Study}

Human resources of each organization as the most important factor in achieving their goals play an important role and is considered the driving force of the organization. Job burnout is defined as emotional exhaustion, depersonalization and reduced personal accomplishment in which teachers are more susceptible to burnout because of their job nature. Since job satisfaction is an important variable and can affect rate and time of burnout, the relationship between job satisfaction and job burnout is studied.

\section{Objective of the Study}

The objective of this research was to investigate the nature of job satisfaction and burnout among Iranian EFL teachers of the universities and schools in Tehran and Ardabil provinces. The main objectives of the empirical section of the present study were:

1. To find out the degree of job satisfaction among Iranian EFL teachers of universities and schools.

2. To explore the degree of burnout among Iranian EFL teachers of universities and schools.

3. To examine the association between teachers' job satisfaction and burnout.

\section{MATERIAL AND METHODS}

\section{Context and Participants}

The participants for this study consisted of 159 Iranian EFL teachers (96 males and 63 females) serving at universities and schools in Tehran and Ardabil provinces. It is necessary to mention that from these participants, sixty-eight teachers worked in universities, while ninety-one teachers worked at schools. These teachers filled out the questionnaires and sent them back in two months, which formed the main data for the study. These participants consisted of both novice and experienced teachers with their active working years ranging from 5 to 35 . They ranged in age from 25 to 65 with most teachers aging between 30 and 40. Upon distributing the questionnaires, all EFL teachers were introduced to the objectives and importance of completing the questionnaires. The confidentiality of the results of the research was also announced to these teachers in order to participate more confidently. 


\section{Instrumentation}

To collect the data, two questionnaires were used, namely, (1) Employee Satisfaction Inventory (ESI) and, (2) Maslach Burnout Inventory- Educators' Survey (MBI-ES).

\section{Employee Satisfaction Inventory (ESI)}

To measure Iranian EFL teachers' job satisfaction levels, Employee Satisfaction Inventory by Koustelios and Bagiatis (2016) was applied. This questionnaire consisits of 24 items, which is used to measure six dimensions of a job: the job itself (four items), pay (four items), promotion (three items), supervision (four items), working conditions (five items) and organization as a whole (four items). The reliability (Cronbach's alpha) for each aspect were: for job itself (0.79), for pay (0.82), for promotion (0.64), for supervision (0.85), for working conditions (0.86) and for organization as a whole (0.79). Responses were given to a five-point scale ranging from strongly agree (Maslach and Jackson, 1981) to strongly disagree (Aziri, 2011).

\section{Maslach Burnout Inventory- Educators' Survey (MBI-ES)}

To measure Iranian EFL teachers' burnout levels, Maslach Burnout Inventory- Educators' Survey (MBI-ES) by Kokkinos (2006) was employed. This 22-item measurement scale consists of three sub-scales, namely Emotional Exhaustion (EE), Depersonalization (DP) and Personal Accomplishment $(P A)$. The frequency scale ranged from zero (never) to six (every day). High scores on emotional exhaustion and depersonalization and low scores on personal accomplishment are indicators of burnout. The scoring is as follows: emotional exhaustion: Nine items 1, 2, 3, 6, 8, 13, 14, 16, 20, which identifies feelings of being emotionally overextended and exhausted by job, depersonalization: Five items 5, 10, 11, 15, 22, which explains a doubtful attitude and impersonal response between oneself and service recipients, and personal accomplishment: Eight items: 4, $7,9,12,17,18,19,21$, which illustrates feelings of efficacy and achievement in employee's work with individuals. The reliability number of the scale was 0.88 .

\section{Data Collection Procedure}

When the questionnaires were piloted with a group of 26 teachers, minor modifications were made in the wordings of some items in order to improve their intelligibility. In addition, the scores obtained from these participants were given into Statistical Package for the Social Sciences (SPSS) and Cronbach's alpha was estimated for the scales (see instruments section above for details) to make sure the scales were sufficiently reliable. It should be noted that a group of colleagues in Tehran and Ardabil provinces of Iran were contacted and asked to distribute the questionnaires among their own colleagues and ask for their cooperation. As mentioned before, the questionnaires were delivered to 72 teachers in person and 87 copies were sent via email or social networks (mainly Telegram and WhatsApp). In total, onehundred and fifty-nine teachers answered the questionnaires and returned them back. These questionnaires were scored and the obtained data were fed into SPSS. It is worth mentioning that the negatively worded items were reverse-coded and the necessary preliminary computations were run to prepare the data for the SPSS.

\section{Data Analysis Procedure}

All data were analyzed employing the Statistical Package for Social Sciences (SPSS version 24). In the present study, descriptive statistics were used to indicate demographic characteristics, dependent and independent variables. This study had six independent variables: teacher specialty, type of school, locale, sex, marital status and seniority. Moreover, nine factors were employed: six from the ESI and three from the MBI questionnaire. To estimate the reliability of subscales, Cronbach's alpha was applied. In addition, Pearson product moment correlations were employed to represent the direction and strength of the relationships between the main variables of the study. An alpha level of .05 was set a priori. MANOVA's and ANOVA's were used to investigate possible differences between the sub-scales of independent variables. It is worth mentioning that ANOVA is used to find the statistical significance of bilateral relationships among different variables. As the purpose of the present research was rather straightforward, it was not considered relevant or necessary to employ advanced data analysis methods and procedures like structural equation modelling.

\section{RESULTS}

As mentioned above, a number of statistical procedures were implemented to answer the research questions. Two questionnaires were used to examine the relationships between EFL teachers' job satisfaction and burnout level. To evaluate the statistical significance of Pearson's correlation coefficient, it was necessary to have bivariate normality, but this assumption was difficult to estimate. Thus, a property of bivariate normality was depended on; in particular, if bivariate normality existed, both variables were normally distributed. Hence, the normality test for both variables was needed. To evaluate the normality of data in the present study, ShapiroWilk test was applied. Based on the results of the normality test in table 1, it can be claimed that teachers' job satisfaction and burnout scores were normally distributed $(p>.05)$.

\begin{tabular}{l|c|c|c}
\multicolumn{1}{c|}{ Shapiro-Wilk } & Statistics & Df & $\boldsymbol{p}$-value \\
\hline Job Satisfaction & 0.957 & 158 & 0.457 \\
\hline Burnout & 0.979 & 158 & 0.513 \\
\hline
\end{tabular}

Table 1: Test of normality, 2019-2020

According to table 2, the Pearson correlation matrix, mean values, Standard Deviation and Cronbach's alpha rates of EFL teachers' burnout and job satisfaction are presented. The findings of the study represent that the burnout and job satisfaction were correlated, since all the sub-scales of job satisfaction were negatively correlated with the main aspect of burnout, being emotional exhaustion. This means that when teachers' emotional exhaustion increases, their perceived job satisfaction decreases and vice versa. 


\begin{tabular}{|c|c|c|c|c|c|c|c|c|c|}
\hline Sub-scales & 1 & 2 & 3 & 4 & 5 & 6 & 7 & 8 & 9 \\
\hline 1. Working conditions 1 & 1 & & & & & & & & \\
\hline 2.Pay & 0.055 & 1 & & & & & & & \\
\hline 3.Promotion & 0.042 & $0.210^{* *}$ & 1 & & & & & & \\
\hline 4.Work itself & $0.265^{* *}$ & -0.052 & 0.037 & 1 & & & & & \\
\hline 5. Supervision & $0.272^{* *}$ & 0.098 & 0.093 & $0.428^{* *}$ & 1 & & & & \\
\hline 6. Organization as a whole & $0.359^{* *}$ & 0.070 & 0.092 & $0.294^{* *}$ & $0.549^{* *}$ & 1 & & & \\
\hline 7.Emotional exhaustion & $-0.170^{* *}$ & -0.097 & $-0.107^{*}$ & $-0.369^{* *}$ & $-0.208^{* *}$ & $-0.157^{* *}$ & 1 & & \\
\hline 8. Personal accomplishment & -0.032 & $0.111^{*}$ & 0.089 & $-0.362^{* *}$ & $-0.134^{* *}$ & $-0.149^{* *}$ & $0.456^{* *}$ & 1 & \\
\hline 9.Depersonalization & $0.152^{* *}$ & $-0.293^{* *}$ & 0.007 & $0.419^{* *}$ & $0.103^{*}$ & 0.033 & $-0.167^{* *}$ & $-0.391^{* *}$ & 1 \\
\hline
\end{tabular}

${ }^{* *} p<0.01 ; * p<0.05$

\section{Table 2: Correlation matrix for MBI and ESI sub-scales, 2019-2020}

Table 3 represents the means, the Standard Deviation, as well Maslach Burnout Inventory sub-scales for the universities and as the $p$-value of the Employee Satisfaction Inventory and schools.

\begin{tabular}{|c|c|c|c|c|c|c|}
\hline & & \multicolumn{2}{|c|}{ Schools ( $n=68)$} & \multicolumn{2}{|c|}{ Universities $(n=91)$} & \multirow{2}{*}{ Sig. } \\
\hline & & $M$ & $S D$ & $M$ & $S D$ & \\
\hline \multirow{6}{*}{$\begin{array}{l}\text { Job Satisfaction } \\
\text { Factors }\end{array}$} & Working conditions & $3.45^{*}$ & 0.772 & $3.72^{*}$ & 0.670 & 0.011 \\
\hline & Pay & 2.08 & 0.850 & 2.21 & 0.900 & 0.111 \\
\hline & Promotion & 2.49 & 0.836 & 2.58 & 0.619 & 0.181 \\
\hline & Work itself & 4.24 & 0.537 & 4.26 & 0.589 & 0.624 \\
\hline & Supervision & 3.93 & 0.923 & 4.09 & 0.757 & 0.050 \\
\hline & Organization as a whole & 3.25 & 0.814 & 3.38 & 0.858 & 0.103 \\
\hline \multirow{3}{*}{ Burnout Factors } & Emotional exhaustion & 20.20 & 10.745 & 20.95 & 10.605 & 0.465 \\
\hline & Personal accomplishment & 39.60 & 6.621 & 40.14 & 6.170 & 0.379 \\
\hline & Depersonalization & 3.22 & 4.110 & 3.14 & 3.715 & 0.838 \\
\hline
\end{tabular}

* = statistically different, $p<0.05$

Table 3: Means, standard deviation, and p. level of the ESI sub-scales for school type, 2019-2020

Considering job satisfaction, the findings revealed that there were statistically significant differences for workplace, $F(6.321)=3.18, p<0.01$. In the separate analysis of variance (ANOVA's) that followed, there were found statistically significant differences for the 'working conditions' $F$ (1.326) $=15.39, p<0.01$. It is necessary to mention that no significant differences were found for the variables 'pay', 'promotion', 'work itself,' 'supervision' and 'organization as a whole'. On the other hand, the factor 'workplace' seems to be associated with the working conditions, as teachers working in schools seemed to be less satisfied than teachers working in universities. According to the burnout, there was no statistically significant difference for the workplace. Therefore, it can be assumed that the workplace type did not influence the sub-scales of burnout, as there was not found any statistically significant difference in this item.

\section{DISCUSSION}

The objective of this research was to examine the relationship between job satisfaction and burnout and to evaluate differences in job satisfaction and burnout between EFL teachers working in universities and schools in Iran. As reported by the results, university teachers had higher job satisfaction and lower burnout levels than those who work in schools. This difference could be due to the diversity in demographic characteristics, the nature of the job, and the workplace. The findings also represented that job satisfaction aspects of EFL teachers had a negative relationship with their burnout aspects. These results also revealed that by increasing teachers' job satisfaction increases, their perceived burnout decreases. Accordingly, experienced teachers were more satisfied with their jobs than novice teachers. In other words, teachers' job satisfaction increased with increasing their experience.

The results obtained were in agreement with findings from other studies, where job satisfaction and burnout had a high negative relationship (Atmaca, 2017; Charalambous, 2012; Daniilidou, 2013; Kara, 2020; Karavasilis, 2019; Papastylianou, Kaila, and Polychronopoulos, 2009; Robinson et al., 2019; Sotirios et al., 2019; Torkaman et al., 2017; Vousiopoulos, et al., 2019; Wisnu, 2019; Yu-Hsia and MeiHsiang, 2019). According to Papastylianou, Kaila, and Polychronopoulos (2009), factors which could possibly influence teachers' job satisfaction, are the existence of strong and consistent social relationships. Moreover, the aspects of teaching as a permanent job and the lack of any formal evaluation also play a pivotal role in the low degrees of burnout (Platsidou and Agaliotis, 2008). In addition, Kara (2020) argued that teachers' burnout and job satisfaction represented significant differences according to gender, marital status, experience and workplace.

According to this study, the five aspects of job satisfaction were negatively related to burnout, except for the aspect of 
pay. In the case of payment, teachers' dissatisfaction with salary resulted in increasing their burnout level. The results of the present study are in line with the results of Kroupis, Kouli, and Kourtessis (2019). Kroupis, Kouli, and Kourtessis pointed out that Greek teachers were more dissatisfied by payment while experiencing medium to low burnout. The problems of living and inequality between salaries and inflation seem to influence the level of burnout in EFL teachers. The findings also represented that by increasing teachers' emotional exhaustion, their job satisfaction decrease. These findings were in line with the results obtained by some of the previously conducted studies (Atmaca, 2017; Bhana and Haffejee, 1996; Kara, 2020; Koeske, et al., 1994; Vousiopoulos, et al., 2019), where job satisfaction and burnout represented medium to a high negative relationship. According to the results of the study, teachers reported high degrees of dissatisfaction regarding promotion, which was in parallel with the study of Tye and O'Brien (2016). On the other hand, some of the researchers (Kroupis, Kouli, and Kourtessis, 2019; Grundy and Blandford, 1999; Vedder and Hall, 2000; Vousiopoulos, et al., 2019) in their studies indicated that Pay, as well as promotion have a positive influence on the levels of burnout and, therefore, the state should improve job satisfaction. In addition, the aspects of burnout related to the supervision and the work itself are negatively associated with the main aspects of burnout, which are depersonalization and emotional exhaustion. On the other hand, these aspects are positively related to one of the main aspects of teachers' burnout namely, lack of personal accomplishment. It implies that those teachers who had low degrees of personal achievements reported high degrees of job satisfaction. According to Kolbadinejad, Ashraf Ganjouei, and Haji Anzehaei (2018), It is notable that the findings represented a significant association between job satisfaction and its components with the enhancement of performance and its sub-scales. Therefore, the low levels of burnout lead to the high levels of job satisfaction. Some of the studies proposed that job satisfaction is related to the two aspects of burnout namely, lack of personal accomplishment and emotional exhaustion (Skaalvik and Skaalvik, 2009; Wisnu, 2019).

The results of the present study are in line with the results of YuHsia and Mei-Hsiang (2019), in which there were significant relationships between the sub-scales of teachers' job satisfaction. Regarding the findings, working conditions are associated with the organization as a whole, the work itself, and the supervision. Further, the work itself is associated with the supervision, the organization as a whole and the working conditions. On the other side, the supervisor is positively associated with the organization as a whole. The findings also showed that the supervisor affects the teacher's attitude towards school and the profession itself. Teacher's stress is influenced by factors like, poor infrastructure, absence of training programs parents' demands, limited state support, influencing, therefore, the degrees of job satisfaction.

According to the above mentioned discussions, burnout is considered to be a potential problem for all EFL teachers, particularly in universities and schools, where teachers have to deal with students and other colleagues. Another substantial point related to the teachers' burnout was its direct and indirect costs and damages. Accordingly, the implementation of measures to control the level of burnout, results in improving teachers' mental health, teaching effectiveness, interpersonal relationships and finally their job satisfaction.

\section{CONCLUSIONS AND IMPLICATIONS}

Effective teachers have a pivotal role in the performance and success of educational systems and different psychological and sociological factors can influence their success and failure. According to Wisnu (2019), job satisfaction has a significant positive effect on the teachers' performance. For this reason, the present research intended to investigate two important factors influencing the performance of EFL teachers. More specifically, it aimed to investigate the interaction and relationship between two determining aspects of EFL teachers' behavior, namely burnout and job satisfaction. One-hundred and fifty-nine Iranian EFL teachers from different universities and schools participated in the study. As the main data collection instruments, two questionnaires were submitted to the participants in three different ways: email, social networks and in person, and they were requested to complete and send them back. After data collection, SPSS version 24 was employed to find the relationship between the main variables. The results of the study represented that, university teachers have higher job satisfaction and lower burnout levels in comparison with those who work in schools. Furthermore, the EFL teachers' job satisfaction aspects have a negative association with their burnout aspects. It was additionally concluded that by increasing teachers' job satisfaction, their perceived burnout decreases.

Because of the important role of teachers in developing their students' achievement and success, some investigators have raised concerns over the competence, well-being and their sense of satisfaction of being a teacher. According to Roy and Kumar (2018), teachers experience burnout due to several responsibilities given to them in the workplace. On the other hand, job satisfaction is a necessary requirement for higher dedication and commitment of teachers toward their responsibilities at the workplace. It was also recommended that teachers should be presented a variety of significant tasks since monotonous and routine work often results in job dissatisfaction. In agreement with the results of Torkaman et al. (2017), lack of satisfaction from teachers' motivational needs over time makes them dissatisfied with the work process leading to job burnout. As a result, interventions to reduce stress and to reinforce resources for self-management are important factors for their job satisfaction.

Any language teaching investors or stakeholders, such as educational policy-makers, teachers, and researchers might benefit from the findings of this research. Moreover, this study can help educators and administrators to better understand the psychological and sociological aspects of EFL teachers and take measures to remove barriers in this regard and foster the achievement of educational objectives. The education policy for EFL teachers should concentrate on developing skills for different aspects of the educational process, because of the teacher's multifaceted role. It has been proposed that teachers should achieve their potential skills and develop the proficiency which are necessary to manage the classroom. EFL teachers are recommended to be trained on how to deal with conditions and challenges related to the social environment of Iran. According to this study, it is recommended to assist the EFL teachers by giving feedback to reduce their job stress and increase job satisfaction. 
This study has different limitations which should be kept in mind in order to interpret the findings. At first, it is necessary to mention that, as the sample included EFL teachers from specific areas, that make it impossible to generalize the findings to other teachers. As a second limitation, the present study did not consider the differences among cultures, religious beliefs, and their educational autonomy. Studying the previously mentioned aspects of EFL teachers are recommended to get more precise conclusions. In spite of the limitations, the findings have provided new insights that deserving additional studies.

Further studies could be intended to investigate deeply into other factors regarding job satisfaction and burnout. Future researches could study whether the fact that Iranian EFL teachers usually work in more than one university or school, could also influence the levels of job satisfaction. Because this parameter was not studied in the present research; therefore, it is a good area of interest for future researches. Further study, determining the relations of burnout and job satisfaction to other variables like commitment, self-efficacy, professional development, engagement, leadership, etc., can be carried out. Developing and extending this study may involve a greater sample size, involving various types of educational workplaces and demographic examples.

\section{REFERENCES}

Anbar, A. and Eker, M. (2008) 'An Examination of Relationship between Burnout and Job Satisfaction among Turkish Accounting and Finance Academicians', Europian Jurnal of Economic and Political Studies, Vol. 1, No. 1, pp. 39-57.

Atmaca, Ç. (2017) 'A burning issue among English teachers: Reflections of in-service teachers on job satisfaction and burnout', International Association of Research in Foreign Language Education and Applied Linguistics, ELT Research Journal, Vol. 6, No. 1, pp. 89-115.

Azeem, S. M. (2010) 'Personality hardiness, job involvement and job burnout among teachers', International Journal of Vocational and Technical Education, Vol. 2, No. 3, pp. 36- 40.

Azeem, S. M. and Nazir, A. N. (2008) 'A study of job burnout among university teachers', Psychology Developing Societies, Vol. 20, No. 1, pp. 51-64. https://doi. org/10.1177/097133360702000103

Aziri, B. (2011) 'Job Satisfaction: A literature Review', Management Research and Practice, Vol. 3, No. 4, pp. 77-86.

Azlina, B. M. K. and Noryati, B. Ch. (2012) The Relationship between work stress and job satisfaction among principal in Melaka, Malaysia, [Unpublished Thesis]. Johor Bahru: Universiti Teknologi Malaysia.

Balkin, R. S., White, G. L. and Bodey, K. J. (2003) 'Do classroom behavior, access to materials, and teaching experience influence teachers leaving the profession?', Arkansas Educational Research and Policy Studies Journal, Vol. 2, pp. 65-79.

Barrick, R. K. (1989) 'Burnout and job satisfaction of vocational supervisors', Journal of Agricultural Education, Vol. 30, No. 4, pp. 35-41. https://doi.org/10.5032/jae.1989.04035

Bhana, A. and Haffejee, N. (1996) 'Relation among measures of burnout, job satisfaction, and role dynamics for a sample of South African child-care social workers', Psychol Reports, Vol. 79, No. 2, pp. 431-434. https://doi.org/10.2466/ pr0.1996.79.2.431

Bibou-Nakou, I., Stogiannidou, A. and Kiosseoglou, G. (1999) 'The relation between teacher burnout and teachers' attributions and practices regarding school behaviour problems', School Psychology International, Vol. 20, pp. 209-217. https://doi. org/10.1177/0143034399020002004

Bilge, F. (2006) 'Examining the burnout of academics in relation to job satisfaction and other factors', Social Behavior and Personality, Vol. 34, No. 9, pp. 1151-1160. https://doi. org $/ 10.1177 / 0143034399020002004$
Blandford, S. (2000) Managing Professional Development in schools, Educational management series, London: Routledge.

Brewer, E. and McMahan-Landers, J. (2003) 'The relationship between job stress and job satisfaction among industrial and technical teacher educators', Journal of Career and Technical Education, Vol. 20, No. 1, pp. 37-50. http://doi.org/10.21061/jcte.v20i1.622

Castillo, J. X. and Cano, J. (2004) 'Factors Explaining Job Satisfaction among Faculty', Journal of Agricultural Education, Vol. 45, No. 3, pp. 65-75. https://doi.org/10.5032/jae.2004.03065

Cephe, P. T. (2010) 'A study of the factors leading English teachers to burnout', Hacettepe University Journal of Education, Vol. 38, pp. 25-34.

Ceylan, A. and Mohammadzadeh, B. (2016) 'Examining the burnout levels of EFL lecturers at the School of Foreign Languages of a State University in Turkey: Manisa Case', International Journal of New Trends in Arts, Sports and Science Education, Vol. 5, No. 3 , pp. 12-23.

Charalambous, E. (2012) Sources of job stress and job burnout among secondary school teachers in the region of Attica. Athens: Charokopion University.

Croom, D. B. (2003) 'Teacher burnout in agricultural education', Journal of Agricultural Education, Vol. 44, No. 2, pp. 1-13. https://doi.org/10.5032/jae.2003.02001

Daniilidou, A. (2013) The Study of Primary Education Teacher Occupational Burnout with Three Alternative Models: The Maslach Model, the Pines Model and the Copenhagen Model, [Unpublished Thesis]. Thessaloniki: Thesis at the University of Macedonia.

Demirel, E. E., and Cephe, T. P. (2015) 'Looking into burnout levels among English language instructors', Journal of Language and Linguistic Studies, Vol. 11, No. 1, pp. 1-14.

Farber, B. A. (1998) 'Tailoring treatment strategies for different types of burnout', $106^{\text {th }}$ Annual Convention of the American Psychological Association, San Francisco, CA, pp. 14-18.

Farshi, S. S. and Omranzadeh, F. (2014) 'The effect of gender, education level and marital status on Iranian EFL teachers' burnout level', International Journal of Applied Linguistics and English Literature, Vol. 3, No. 5, pp. 128-133. http://dx.doi.org/10.7575/ aiac.ijalel.v.3n.5p.128

Gavish, B. and Friedman, I. A. (2010) 'Novice teachers' experience of teaching: a dynamic aspect of burnout', Social Psychology of Education, Vol. 13, pp. 141-167. https://doi.org/10.1007/ s11218-009-9108-0 
Grundy W. and Blandford S. (1999) 'Developing a Culture for Positive Behaviour Management', Emotional and Behavioural Difficulties, Vol. 4, No. 3, pp. 5-9. https://doi. org/10.1080/1363275990040302

Güven, L. Ç. (2010) Burnout Levels of English Lecturers Working for Preparatory Schools of Foundation Universities in Istanbul, [Unpublished Master's Thesis]. Kars: Kafkas University.

Hastings R. P. and Bham M. S. (2003) 'The relationship between student behavior patterns and teacher burnout', School Psychology International, Vol. 24, No. 1, pp. 115-127. https://doi. org/10.1177/0143034303024001905

Higgins E. T. (1987) 'Self-discrepancy: A theory relating self and affect', Psychological Review, Vol. 94, No. 3, pp. 319-340. https:// doi.org/10.1037/0033-295X.94.3.319

Jarvis M. (2002) 'Teacher stress: A critical review of recent findings and suggestions for future research directions', Stress News, Vol. 14 , No. 1, pp. 12-16.

Johnson S., Cooper C., Cartwright S., Donald I., Taylor P. and Millet C. (2005) 'The experience of work-related stress across occupations', Journal of managerial psychology, Vol. 20, No. 2, pp. 178-187. https://doi.org/10.1108/02683940510579803

Kara S. (2020) 'Investigation of job satisfaction and burnout of visual arts teachers', International Journal of Research in Education and Science, Vol. 6, No. 1, pp. 160-171. https://doi.org/10.46328/ijres. $\underline{\mathrm{v} 6 \mathrm{i} 1.817}$

Karavasilis G. (2019) 'Work satisfaction or burnout and their impact on innovative work behavior of Greek teachers', Journal of Contemporary Education Theory \& Research, Vol. 3, No. 2, pp. 3-10. https://doi.org/10.5281/zenodo.3635027

Kırılmaz A. Y., Çelen Ü. and Sarp N. (2003) 'İlköğretimde çalışan bir öğretmen grubunda tükenmişlik durumu araştırması', İlkögrretimOnline, Vol. 2, No. 1, pp. 2-9.

Koeske G. F., Kirk S. A., Koeske R. D. and Rauktis M. B. (1994) 'Measuring the Monday blues: validation of a job satisfaction scale for the human services', Social Work Research, Vol. 18, No. 1, pp. 27-35. https://doi.org/10.1093/swr/18.1.27

Kokkinos C. M. (2006) 'Factor structure and psychometric properties of the Maslach Burnout Inventory Educators Survey among elementary and secondary school teachers in Cyprus', Stress Health, Vol. 22, No. 1, pp. 25-33. https://doi.org/10.1002/smi.1079

Kolbadinejad M., Ashraf Ganjouei F. and Haji Anzehaei Z. (2018) 'Performance Evaluation Model according to Performance Improvement and Satisfaction of the Staff in the Individual Sports Federations and Federations with Historical Aspect', Annals of Applied Sport Science, Vol. 6, No. 4, pp. 59-671. https://doi. org/10.29252/aassjournal.6.4.59

Konakay G. and Altaş S. S. (2011) 'Akademisyenlerde tükenmişlik ve iş tatmini düzeylerinin demografik değişkenler açısından incelenmesi: Kocaeli Üniver-sitesi örneği', SAÜ Fen Edebiyat Fakültesi Dergisi, Vol. 2, pp. 35-71.

Konert, E. (1997) Relationship among middle-school teacher burnout, stress, job satisfaction and coping styles, [Unpublished doctoral dissertation]. Detroit: Wayne State University.

Koruklu N., Feyzioglu B., Ozenoglu-Kiremit H. and Aladag E. (2012) 'Teachers' burnout levels in terms of some variables', Educational Science: Theory and Practice, Vol. 12, No. 3, pp. 1823-1830.

Koustelios A. D. and Bagiatis K. (2016) 'The Employee Satisfaction Inventory (ESI): Development of a Scale to Measure Satisfaction of Greek Employees', Educational and Psychological Measurement, Vol. 57, No. 3, pp. 469-476. https://doi. org/10.1177/0013164497057003008
Kroupis I., Kouli O., and Kourtessis T. (2019) 'Physical Education Teacher's Job Satisfaction and Burnout Levels in Relation to School's Sport Facilities', International Journal of Instruction, Vol. 12, No. 4, pp. 579-592. https://doi.org/10.29333/ iji.2019.12437a

Kurtoğlu, Ü. (2011) An Evaluation of ELT Teachers' Vocational Burnout According to Some Variables, [Unpublished Master]. Kars: Thesis.Kafkas University.

Lackritz J. R. (2004) 'Exploring burnout among university faculty: incidence, performance, and demographic issues', Teaching and Teacher Education, Vol. 20, pp. 713-729. https://doi. org/10.1016/j.tate.2004.07.002

Landsman M. J. (2001) 'Commitment in public child welfare.' The Social Service Review, Vol. 75, No. 3, pp. 386-419. https:// doi.org/10.1086/322857

LeCompte, M. D. and Dworkin, A. G. (1991) Giving up on school: Student dropouts and teacher burnouts. Newbury Park, CA: Corwin Press.

Lee J. S. (1990) 'How healthy are agriculture teachers?' The Agricultural Education Magazine, Vol. 62, No. 12, pp. 6, 21.

Lim, Y. Ch. (2005) Relationship between work stress and job satisfaction among technical teachers in Technical Secondary School Kedah, Malaysia, [Unpublished Thesis], Johor Bahru: Universiti Teknologi Malaysia.

Locke E. A. (1976) 'The Nature and Causes of Job Satisfaction', in: Dunnette, M. D., (ed.), Handbook of Industrial and Organizational Psychology, Vol. 1, pp. 1297-1343.

Maslach, C. (1982) Burnout: The Cost of Caring. Englewood Cliffs, New Jersey: Prentice Hall.

Maslach, C., and Leiter, M. P. (1997) The truth about burnout. San Francisco: Jossey-Bass.

Maslach C. and Jackson S. E. (1981) 'The measurement of experienced burnout', Journal of Organisational Behaviour, Vol. 2, No. 2, pp. 99-113. https://doi.org/10.1002/ job.4030020205

Maslach, C., Jackson, S. E. and Leiter, M. P. (1996) Maslach Burnout Inventory Manual, 3rd edition, Palo Alto, CA: Consulting Psychologists Press.

Maslach C., Schaufeli W. B. and Leiter M. P. (2001) 'Job burnout', Annual Review of Psychology, Vol. 52, pp. 397-422. https:// doi.org/10.1146/annurev.psych.52.1.397

McCormick J. (2011) 'Teachers' attributions for stress and their relationships with burnout', International Journal of Educational Management, Vol. 25, No. 3, pp. 278-293. https://doi.org/10.1108/09513541111120114

Norul Azlin, B. I. (2005) Stress among UPSR teachers in Pendang, [Unpublished Thesis]. Johor Bahru: Universiti Teknologi Malaysia.

Özkanal Ü. and Arikan N. (2010) 'Investigation of Burnout among Instructors Working at ESOGU Preparatory School', English language teaching, Vol. 3, No. 1, pp. 166-172. https://doi. org/10.5539/elt.v3n1p166

Öztürk G. (2013) 'Job Burnout Experienced by Turkish Instructors of English Working at State Universities', International Online Journal of Educational Sciences, Vol. 5, No. 3, pp. 587-597.

Papastylianou A., Kaila M. and Polychronopoulos M. (2009) 'Teachers' burnout, depression, role ambiguity and conflict', Social Psychology of Education, Vol. 12, No. 3, pp. 295-314. https://doi.org/10.1007/s11218-008-9086-7 
Platsidou M. and Agaliotis I. (2008) 'Burnout, Job Satisfaction and Instructional Assignment-related Sources of Stress in Greek Special Education Teachers', International Journal of Disability, Development and Education, Vol. 55, No. 1, pp. 61-76. https:// doi.org/10.1080/10349120701654613

Petty G. C., Brewer E. W. and Brown B. (2005) 'Job Satisfaction among Employees of a Youth Development Organization', Child and Youth Care Forum, Vol. 34, No. 1, pp. 57-75. https://doi. org/10.1007/s10566-004-0882-8

Rahman U., Wan Sulaiman W., Nasir R. and Omar F. (2014) 'The Role of Job Satisfaction as Mediator in the Relationship between Self-Efficacy and Organizational Citizenship Behavior among Indonesian Teachers', International Journal of Business and Social Science. Vol. 5, No. 9, pp. 257-260.

Rakovec-Felser Z. (2011) 'Professional Burnout as the State and Process - What to Do?' Collegium Anthropologist, Vol. 35, No. 2, pp. 577-585.

Robinson O. P., Bridges Sh. A., Rollins L. H., and Schumacker R. E. (2019) 'A study of the relation between special education burnout and job satisfaction', Journal of Research in Special Educational Needs, Vol. 19, No. 4, pp. 295-303. https://doi.org/10.1111/1471$\underline{3802.12448}$

Roy J. and Kumar A. (2018) 'Relationship between Burnout and Job Satisfaction among the Teachers in Engineering Institutes', International Journal of Mechanical Engineering and Technology, Vol. 9, No. 1, pp. 705-717.

Schaufeli, W. B. and Enzmann, D. (1998) The Burnout Companion to Study and Practice. London: Taylor and Francis.

Schmidt K. H., Neubach B. and Heuer H. (2007) 'Self-control demands, cognitive control deficits, and burnout', Work and Stress, Vol. 21, No. 2, pp. 142-154. https://doi.org/10.1080/02678370701431680

Seashore S. and Taber T. (1975) 'Job Satisfaction Indicators and Their Correlates', American Behavioral Scientist, Vol. 18, No. 3, pp. 333-368. https://doi.org/10.1177/000276427501800303

Sitohang, N. (2004) Asuhan Keperawatan Pada anak Child Abuse. Medan: USU Digital Library.

Skaalvik E. M. and Skaalvik S. (2009) 'Does school context matter? Relations with teacher burnout and job satisfaction', Teaching and Teacher Education, Vol. 25, No. 3, pp. 518-524. https://doi. org/10.1016/j.tate.2008.12.006

Sotirios V., Olga K., Thomas K., Efstratia T., and Dimos D. (2019) 'Job Satisfaction and Burnout among Greek Teachers and Physical Education Teachers: A Comparison in Minority and Public Sector Schools in Thrace', Annals of Applied Sport Science, Vol. 7, No. 4, pp. 52-60. https://doi.org/10.29252/aassjournal.786

Soroor R., Afsaaneh G. and Zargham G. (2015) 'A study of contextual precursors of burnout among EFL Teachers', International Journal of Research Studies in Psychology, Vol. 4, No. 1, pp. 13-24. https://doi.org/10.5861/ijrsp.2015.1025

Spector P. E. (1985) 'Measurement of Human Service Staff Satisfaction: Development of the Job Satisfaction Survey', American Journal of Community Psychology, Vol. 13, No. 6, pp. 693-713. https://doi.org/10.1007/BF00929796

Straquadine G. S. (1990) 'Work, is it your drug of choice?' The Agricultural Education Magazine, Vol. 62, No. 12, pp. 11-12, 21.
Tan, S. L. (2006) The effect of personality on job satisfaction and teacher job stress, [Unpublished Thesis]. Johor Bahru: Universiti Teknologi Malaysia.

Taris T. W. (2006) 'Is there a relationship between burnout and objective performance: Critical review of 16 studies?', Work and Stress, Vol. 20, No. 4, pp. 316-334. https://doi. org/10.1080/02678370601065893

Terason S. (2018) 'The Effect of Conflict Management in Thai PublicSector Sport Organizations on Employee Job Satisfaction and Perceived Organizational Performance', Academy of Strategic Management Journal, Vol. 17, No. 1, pp. 168-172.

Torkaman F., Farhang S., Zakerian S. A., Torkaman M., and Keramati Niaragh H. (2017) 'A study on the effect of job burnout and stress on job satisfaction among teachers of exceptional school', Pharmacophore, Vol. 8, No. 5, pp. 18-24.

Troman, G. and Woods, P. (2001) Primary teachers'stress, New York: Routledge/Falmer.

Tukiran, N. (2014) Assessment literacy among prospective technical teachers in public universities of the South Zone, [Unpublished Thesis]. Batu Pahat: Universiti Teknologi Tun Hussein Onn Malaysia.

Tye B. B. and O'Brien L. (2016) 'Why are Experienced Teachers Leaving the Profession?' Phi Delta Kappan, Vol. 84, No. 1, pp. 24-32. https://doi.org/10.1177/003172170208400108

Van Jaarsveld, J. (2004) The relationship between burnout, coping, and sense of coherence amongst engineers and scientists, [Unpublished doctoral dissertation]. Pretoria: University of South Africa.

Vedder R. and Hall J. (2000) 'Private school competition and public school teacher salaries', Journal of Labor Research, Vol. 21, No. 1, pp. 161-168. https://doi.org/10.1007/s12122-000-1010-7

Vousiopoulos S., Kouli O., Kourtessis T., Tsitskari E. and Tsitskari D. (2019) 'Job Satisfaction and Burnout among Greek Teachers and Physical Education Teachers', A Comparison in Minority and Public Sector Schools in Thrace. Annals of Applied Sport Science, Vol. 7, No. 4, pp. 52-60. https://doi.org/10.29252 aassjournal.786

Wagner, J. and Hollenbeck, J. (1992) Management of Organizational Behavior, New Jersey: Prentice Hall

Weisberg J. and Sagie A. (1999) 'Teachers' physical, mental, and emotional burnout: Impact on intention to quit', Journal of Psychology, Vol. 133, No. 3, pp. 333-339. https://doi. org/10.1080/00223989909599746

Wisnu P. (2019) 'The relationship among emotional exhaustion, job satisfaction, performance, and intention to leave', Advances in Management \& Applied Economics, Vol. 9, No. 1, pp. 21-29.

Wu G., Duan K., Zuo J., Yang J. and Wen S. (2016) ‘System Dynamics Model and Simulation of Employee Work-Family Conflict in the Construction Industry', International Journal of Environmental Research and Public Health, Vol. 13, No. 11. https://doi. org/10.3390/ijerph13111059

Yu-Hsia L. and Mei-Hsiang L. (2019) 'Exploring the Relationship Between Burnout and Job Satisfaction Among Clinical Nurses', European Scientific Journal, Vol. 15, No. 3, pp. 449-460. http:// dx.doi.org/10.19044/esj.2019.v15n3p449 